LA-UR-97: $315 \mathbf{6}^{-}$

Approved for public release; distribution is unlimited

\title{
Title: Studies of Dynamical Processes Affecting Global Climate
}

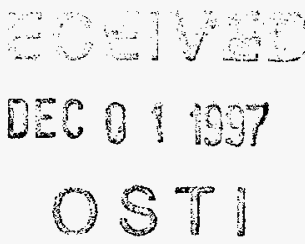

Author(s):

C. Keller, EES-IGPP; D. Cooper, W. Eichinger, S. Elliott, and J. Kao, EES-8; D. Holm, T-7; L. Margolin, X-HM; J. Robinson, CST-6; and P. Weber, NIS-2

M. Ghil, R. Turco, F. Chen, A. Quintinar, A. W. Robertson, M. Shen, and X.P. Zhao, UC-Los Angeles

R. Somerville, J. Roads, S. Chen, W. S. Smith, S. Yang, and C. Norris, UC-San Diego

K. Friehe, E. Titi, P. Feuhrer, L. Hudgins, H. Chen, S. Hauk, and S. Wynne, UC-Irvine

M. Parlange, J. Albertson, T. Ortenburger, and T. Cahill, UC-Davis K. Prather, UC-Riverside

Submitted to:

DOE Office of Scientific and Technical Information (OSTI)

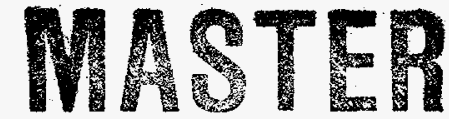

DESTIBUTON OF THIS DOCUMENT is UMUMUED

\section{Los Alamos}

NATIONAL LABORATORY

Los Alamos National Laboratory, an affirmative action/equal opportunity employer, is operated by the University of California for the U.S. Department of Energy under contract W-7405-ENG-36. By acceptance of this article, the publisher recognizes that the U.S. Government retains a nonexclusive, royaltyIree license to publish or reproduce the published form of this contribution, or to allow others to do so, for U.S. Government pumoses. Los Alamos National Laboratory requests that the publisher identify this article as work performed under the auspices of the U.S. Departmert of Energy. Los Alamos National Laboratory strongly supports academic freedom and a researcher's right to publish; as an institution, however, the Laboratory does not endorse the viewpoint of a publication or guarantee its technical correctness. 


\section{DISCLAIMER}

This report was prepared as an account of work sponsored by an agency of the United States Government. Neither the United States Government nor any agency thereof, nor any of their employees, makes any warranty, express or implied, or assumes any legal liability or responsibility for the accuracy, completeness, or usefulness of any information, apparatus, product, or process disclosed, or represents that its use would not infringe privately owned rights. Reference herein to any specific commercial product, process, or service by trade name, trademark, manufacturer, or otherwise does not necessarily constitute or imply its endorsement, recommendation, or favoring by the United States Government or any agency thereof. The views and opinions of authors expressed herein do not necessarily state or reflect those of the United States Government or any agency thereof. 


\section{DISCLAMMER}

Portions of this doecoment mosy be illegible in electronic imoge prodnets Imoges are produced from the best availabie original docoment 


\title{
Studies of Dynamical Processes Affecting Global Climate
}

\author{
Charles Keller*, D. Cooper, W. Eichinger, S. Elliott, D. Holm, \\ J. Kao, L. Margolin, J. Robinson, and P. Weber \\ Los Alamos National Laboratory \\ Michael Ghil, Richard Turco, F. Chen, A. Quintinar, \\ A. W. Robertson, M. Shen, and X.P. Zhao \\ University of California-Los Angeles \\ Richard Somerville, John Roads, Shyh Chen \\ University of California-San Diego/Scripps
}

Karl Friehe, Edris Titi, P. Feuhrer, L. Hudgins, H. Chen, S. Hauk, S. Wynne

Univeristy of California-Irvine

W. S. Smith, S. Yang, and C. Norris

University of California-San Diego

Marc Parlange, J. Albertson, T. Ortenburger, and T. Cahill

University of California-Davis

Kimberly Prather

University of California-Riverside

\begin{abstract}
This is the final report of a three-year, Laboratory Directed Research and Development project at the Los Alamos National Laboratory (LANL). The main objective was, by a combined theoretical and observational approach, to develop improved models of dynamic processes in the oceans and atmosphere and to incorporate them into large climate codes, chiefly in four main areas: numerical physics, chemistry, water vapor, and oceanatmosphere interactions. Main areas of investigation included studies of: cloud parameterizations for global climate codes, Lidar and the planetary boundary layer, chemistry, climate variability using coupled oceanatmospheric models, and numerical physical methods. This project employed a unique approach that included participation of a number of University of California faculty, postdoctoral fellows and graduate students who collaborated with Los Alamos research staff on specific tasks, thus greatly enhancing the research output. Overall accomplishments during the three years of this project were: (1) first two- and three-dimensional remote sensing of the atmospheric planetary boundary layer using Lidars, (2) modeling of 20-year cycle in both pressure and sea surface temperatures in North Pacific, (3) modeling of low frequency internal variability, (4) addition of aerosols to stratosphere to simulate Pinatubo effect on ozone, (5) development of fast, comprehensive chemistry in the troposphere for urban pollution studies, (6) new prognostic cloud parameterization in global
\end{abstract}

*Principal Investigator, E-mail: cfk@lanl.gov 
atmospheric code remedied problems with North Pacific atmospheric circulation and excessive equatorial precipitation, (7) development of a unique aerosol analysis technique, the aerosol time-of-flight mass spectrometer (ATOFMS), which allows real-time analysis of the size and chemical composition of individual aerosol particles, and (8) numerical physics applying Approximate Inertial Manifolds to ocean circulation.

\section{BACKGROUND AND RESEARCH OBJECTIVES}

This project studied major aspects of the interactions between the Earth's atmosphere and its oceans. It is generally recognized that current global climate codes are deficient in the physics and chemistry necessary for proper understanding of climate dynamics and for predicting climate change. Even natural variability is poorly understood and so predicting the degree and timing of possible global warming does not yet have the credibility needed for policy planning. This project has attempted to contribute to a better understanding of critical aspects of the important dynamical processes governing the Earth's oceans and atmosphere. The main objective was, by a combined theoretical and observational approach, to develop improved models of dynamic processes in the oceans and atmosphere and to incorporate them into large climate codes, chiefly in three main areas: chemistry, water vapor, and ocean/atmosphere interactions. Main subprojects included studies of:

- improved cloud parameterization in global climate models ;

- coupled ocean/atmosphere modeling of interdecadal variability in the northern mid-latitude oceans;

- modeling of low frequency internal variability in the ocean/atmospheric system;

- lidar observation of water vapor and turbulence in the ocean/atmosphere boundary layer;

- stratosphere and troposphere photochemistry modeling;

- heterogeneous laboratory chemistry; and

- numerical physics descriptions of ocean dynamics.

\section{IMPORTANCE TO LANL'S SCIENCE AND TECHNOLOGY BASE AND NATIONAL R\&D NEEDS}

This project has made a strong contribution to the Laboratory's core competencies, particularly in Earth and Environmental Systems, and Theory, Modeling and High- 
Performance Computing. It enhanced capabilities in numerical physics, computer modeling of large dynamical systems, multidimensional remote sensing of the atmosphere, and laboratory experiments. It had direct impact on both Laboratory and Department of Energy (DOE) missions as regards the need to assess impacts on our atmosphere and climate from energy production (DOE programs ARM and CHAMMP for example), and in support of the new State Department initiative that recognizes environmental change as important to national security. This recent elevation of global environmental change to importance in national security has resulted in a major Memorandum of Understanding (MOU) among DOE, the Environmental Protection Agency (EPA), and the Department of Defense (DoD) and could draw heavily on the strengthened core competencies at Los Alamos. Thus this project has been responding to clearly defined national $R \& D$ needs.

\section{SCIENTIFIC APPROACH AND ACCOMPLISHMENTS}

This project follows a fundamental recognition that the wealth of observational and theoretical work on individual climate processes will be difficult to unify unless integrated by large computer codes that simulate ocean and atmospheric dynamics in a self-consistent manner. The general approach centers around use of global ocean and atmospheric general circulation models (GCMs). The scientific approach was to incorporate both observational data and theoretical models of processes into these large codes in order to improve their ability to simulate the ocean/atmospheric system. The organizational approach to this complex problem was fairly innovative. The principal investigator was able to gather together a team of Laboratory and University of California (UC) participants to work on a variety of important problems confronting the global climate community. While the individual subprojects were distinct, their combined effect has been to enhance the basic Earth and Environmental Systems core competency of the Laboratory since these elements are the very ones needed to make substantial improvements in national climate codes that will be used for analysis and assessment of the impacts of anthropogenic input to the atmosphere. The individual subprojects combined the strengths of both Los Alamos and $\mathrm{UC}$, and included laboratory experimental facilities, remote sensing field equipment, and high performance computers, as well as expertise in atmospheric chemistry, theoretical fluid dynamics, cloud physics, numerical physics and analytical mathematics. 


\section{Major Accomplishments}

Accomplishments have been numerous. A wealth of new understanding of the climate system and improvements in physics and modeling have been accomplished. Some of the major accomplishments are detailed below.

\section{Interannual-to-Secular Variability of the Extratropical (Mid- Latitude) Ocean}

Recent studies have shown organized climate variability on time scales of years to centuries. The wind-driven circulation of the tropical oceans is known to play a major role in global interannual climate variability. It is becoming increasingly plausible that the thermohaline circulation (THC) of the global ocean is playing a similar role in interdecadal and secular variability. This subproject has been studying such variability in models of differing complexity in the mid-latitude (extratropical) regions of both the Atlantic and Pacific Oceans. Using a simplified version of the Bryan-Cox global ocean model with $4 \times 4$ degree resolution, two distinct interdecadal oscillations were found. Encouraged by this, participants added an interacting atmosphere and runs were done with successively more complex atmospheric components and different salinity factors. At each increase in complexity, interdecadal variability was found and was due to changing values of surface ocean density. With this basic understanding of the roles of various density-affecting mechanisms, a large, complex run of 500 years was made by coupling a full global atmospheric model (Cubasch et al. 1992) to a global ocean model including a thermodynamic ice model. A statistically significant cycle in sea surface temperature (SST) variability with a period of about 18 yrs was found. A similar variability was found in pressure variations in the atmosphere. Figure 1 shows SST and current vectors for three times in this cycle. The vertical ocean temperature structure anomalies lag both the pressure and SST anomalies indicating that the ocean is not in equilibrium with the atmosphere and that the ocean-atmosphere interaction plays a crucial role in the oscillation. A similar 20-year cycle has been observed in the Northern Pacific and so this simulation is of great significance since it is being recognized that the interannual El Niño/Southern Oscillation in the equatorial Pacific beats with this interdecadal oscillation to greatly affect weather and climate in Western North America.

A final study (looking for interannual variability) was done analyzing two 20-year integrations of the high-resolution POP ocean global code being run at Los Alamos (Smith et al., 1992) at a 2/3 degree resolution. No significant variability was found, most probably owing to the need for higher resolution to produce the needed nonlinear advection 
of momentum. Eddy resolving resolution (about 1/6 degree) appears to be a prerequisite for this type of oscillation and tests with POP at this higher resolution need to be done in future.

In summary, over the three years of this project ever more complex ocean/atmosphere models have shown not only the existence of interdecadal variability in the large extra-tropical ocean basins, but the mechanisms producing it. In view of our increasing need to understand climate variability in general and in North America in particular, this has been a highly significant finding.

\section{Low-Frequency Internal Variability in a Simplified General Circulation Model}

A critical problem in prediction of climate change is understanding the long-term natural variability of the climate system and the causes of this variability. This subproject studied variability up to 100 years using a simplified version of the National Meteorological Center's medium-range forecast global spectral model, which was driven by time-varying, empirical forcings of SST and solar radiation (Chen et al, 1993). Due primarily to the empirical nature of these forcings, the model reproduced in an acceptable manner major climatological features and observed short-term variation amplitude. Empirical Orthogonal Function (EOF) analysis of the results showed a red spectrum variability in the range 1-50 years. Perhaps the most significant finding of this study was that regional circulation patterns associated with the low-frequency variability also vary with very long time scales! In particular, two significant circulation patterns associated with variation over the Pacific/North American area showed up: one has the familiar teleconnection between equatorial Pacific and North America (generally an east-west pattern), and the other has a north-south oscillation. Both are centered on North America. The behavior is such that each is relatively stable for years, but then changes gradually to the other. Such bi-modal behavior has considerable significance for understanding climate change in the long term.

\section{Physics of the Planetary Boundary Layer and the Surface Atmosphere Interface from Lidar Observations}

The overall objective of this subproject is to analyze lidar remote sensing data to improve current understanding of surface-atmosphere interfaces, and thus lead to improved parameterizations of the surface fluxes of water vapor at regional scales for climatic and hydrologic processes. Analysis of three data sets was done. 
- In a study of basic behavior of evaporation from the ground into the planetary boundary layer, water-vapor Raman lidar data taken at UC Davis has been used to measure the stability correction function for water-vapor in unstable cases. While the data obtained do not significantly differ from the commonly accepted Businger-Dyer function, the large number of measurements (over 41,000) make the case much stronger for the accuracy of this function.

- The second data set was taken from a ship during the Central Equatorial Pacific Experiment (CEPEX). Water vapor ocean/atmosphere fluxes were determined for the duration of the voyage from the predominantly warm Western Pacific to the cooler region east of the International Date Line. Fluxes were found to be a strong function of wind velocity, but also increased with increasing sea surface temperature. Their behavior coupled with other measurements aboard ship has allowed development of a method to determine the trigger point of SST for the onset of storm-producing deep convection. The elastic back-scatter lidar observed clouds in the atmospheric boundary layer (ABL) and to $20 \mathrm{~km}$ heights (Figures 2 and 3). Careful study of this data set has resulted in a method for determining cloud albedo, which if proven accurate, will greatly enhance our ability to determine the atmospheric radiation budget in the presence of cloud.

- Analysis of the lidar data taken over Barcelona will lead to a masters thesis. The data allows determination of the rate of growth of the boundary layer each morning, the effect of sea breeze, and an examination of the so-called "heat island" effect.

Related to this lidar work is development of a new way to analyze turbulence in the ABL over the ocean. Turbulence is the mechanism that transports heat, water vapor, and momentum between the ocean and the atmosphere. In climate and other studies of the coupled ocean-atmosphere system, the primary quantities of interest are the turbulent fluxes of sensible heat, water vapor (proportional to the latent heat flux from the ocean), and momentum. The study of turbulence has traditionally been viewed by statistical and Fourier decomposition techniques. With the advent of advanced computer models, it is desirable to look at the structure of atmospheric turbulence in detail to ascertain if dominant ubiquitous structures exist that are amenable to modeling. The recent interest in wavelet analysis to turbulence prompted its application and extension to atmospheric turbulence in the marine boundary layer. In particular, the procedure for the bivariate wavelet analysis was developed. The turbulent fluxes, by Reynolds averaging, are the covariances between the vertical component of the velocity vector and the temperature (for heat flux), water vapor 
concentration (for latent heat flux) and horizontal wind vector (for wind stress). In Fourier analysis, the frequencies or scale lengths of the covariances are analyzed with crossspectral analysis of the two variables. Wavelet analysis had heretofore been developed for one variable (univariate analysis). Therefore, it was required to develop the theory and applications for bivariate wavelet analysis.

A data set of three-component velocity and air temperature obtained in the marine layer at $8 \mathrm{~m}$ above the sea in homogeneous conditions was available for analysis. Mathematical development of bivariate wavelet analysis was undertaken. The method was then applied to the high Reynolds number data set of marine-layer atmospheric turbulence. The results have shown the utility of bivariate wavelet scale-o-grams in identifying the dominant features of the turbulence. In particular, the first moment of the cross scale-ogram was used to identify dominant flux events. For the marine atmospheric boundarylayer data at $8 \mathrm{~m}$ above the sea at a wind speed of $11 \mathrm{~m} / \mathrm{s}$, there were two main contributions to the momentum and heat fluxes: one at a horizontal length scale of about $60 \mathrm{~m}$, and the other at about $2000 \mathrm{~m}$. These contributions were of opposite sign: the small-scale 60-m eddies were contributing to the "normal" turbulent mixing of momentum transfer downward from the wind to the sea, and upward heat transfer from the warmer ocean surface to the cooler air. At $2000 \mathrm{~m}$, however, the signs of these flux contributions reversed: momentum was upward and heat flux down. The larger-scale features are believed to be due to a type of secondary flow in the boundary layer, since the scale of $2000 \mathrm{~m}$ is close to an approximate boundary-layer depth. This new method may prove most useful in analysis of lidar data in the ABL.

\section{Improving Cloud Parameterizations in a Global Atmospheric Model}

Perhaps the most important and least well understood physical processes in the energy budgets of global atmospheric models are the role of clouds. Given the necessarily coarse resolution of these global models, clouds can seldom be treated except by a subgridscale parameterization. This subproject has supported an intensive effort to rethink and redo parameterizations of both low-level stratiform clouds (using an improved version of the model due to Sundqvist (1988)) and those produced by deep convection (improved Arakawa-Schubert method--Kao 1992), as well as the resultant ice plumes that form downwind of them. The new parameterization (called SUNAS) was a "prognostic" model in that condensation, clouds, and cloud water were determined from the ambient state of the atmosphere in the code, not determined from empirical prescriptions involving largescale conditions. SUNAS was developed and first tested against data from regional studies 
before being introduced in the global circulation code $\mathrm{CCM} 2$, developed at the National Center for Atmospheric Research (NCAR). For example, the cloud formulation was used to simulate the San Nicholas Island- FIRE 1987 Observational Campaign,which observed the behavior of marine stratocumulus cloud decks. The simulation attempted to simulate the varying height and thickness of the cloud deck over a several day period. Observed diurnal variations in cloud top height could only be simulated by varying boundary layer subsidence (also observed), but required additional drying during subsidence which was not observed. The model predicted that such drying should be looked for in future observational efforts.

Finally, the full SUNAS has been put into the CCM2. Initial runs are showing significant improvement in the hydrological cycle although some regional problems have been found. The most impressive result is that the persistent wintertime North Pacific weather pattern, which has been simulated incorrectly by the CCM2, has now been corrected to give the observed position of the pressure ridge at the edge of the North American continent and the resultant correct wind directions over the Pacific. SUNAS has also reduced the incorrectly large precipitation patterns over the western equatorial Pacific and over Eastern Brazil (Figure 4). Thus, SUNAS has corrected some significant errors of the cloud parameterization currently used in CCM2 and offers promise of further improvements as ocean/atmosphere moisture fluxes are improved.

\section{Atmospheric Chemistry}

This subproject pursued three efforts: (a) to introduce fast, efficient chemistry packages into regional and global atmospheric codes, (b) to study properties of atmospheric aerosols in the laboratory, and (c) to model sulfur emissions across the Arctic with a global atmosphere code.

\section{(a) Modeling of Regional to Global Scale Issues in Tropospheric}

Photochemistry. The goal here was development of tropospheric chemistry models that are appropriate for use in large-scale, three-dimensional transport frameworks. The research has also led to insights into several topical issues in lower atmospheric photochemistry. Background for the UCLA/LANL collaboration has been discussed in several review/preview publications (Elliott et al., 1993a,b; 1995a). Chemical transformations in the lowest few kilometers of the atmosphere influence the distributions and concentrations of methane, the hydroxyl radical, ozone precursors such as the volatile organics and the nitrogen oxides, and ozone itself. Methane and ozone act as greenhouse gases in the troposphere, ozone is a pollutant with serious health and agricultural effects, 
the hydroxyl is the chief initiator of oxidation processes in the atmosphere, and the nitrogen oxides control crucial kinetic titration points in the ozone production/removal system.

The project derives ultimately from global-scale three-dimensional modeling of ozone chemistry conducted at Los Alamos to investigate the effects of nitrogen oxide injections into the stratosphere during nuclear winter scenarios. Scientists at both UCLA and Los Alamos were interested in extending the simple hydrogen-nitrogen oxide scheme included in the nuclear winter studies to the full range of atom types influencing the ozone layer. However, representation of the complete photochemistries of chlorine, bromine and methane required many dozens of chemical reactions, far more than are typically inserted into global tracer coding. A specialized combination of fast, family-based numerics and automated mechanism setup was instituted to handle the problems arising. A factor of 100 speedup for routines involved in chemistry computations is typical for well designed coding on Cray vector machines. Iteration and matrix inversion were avoided in large measure because species partitioning was performed through family internal implicit integrations sufficiently stabilizing so that a forward Euler method could be applied. The program has been applied to simulate polar ozone depletions and the effects of Pinatubo sulfuric acid aerosols on the stratospheric ozone layer (Zhao et al. 1995 and 1996). The sulfate particles are capable of activating chlorine reservoirs such as chlorine nitrate while storing nitrogen oxides as nitric acid. The resulting activation of chlorine oxide radicals can exert a strong influence on stratospheric ozone levels.

More recently, a tropospheric version of the family routines was constructed, and an extensive series of tests and preliminary applications performed. To the baseline stratospheric chemistry mechanism have been added six nonmethane hydrocarbons (NMHC) capable of acting as surrogates for the entire global organic system. The new organics include ethane, ethylene, propane, propylene, isoprene and acetylene, along with all of their stable and radical oxidation products. The number of photochemical reactions in the model is now well over 200 . However, the numerical streamlining perfected in the stratosphere renders the program fast enough for global three-dimensional simulations. After Shen had completed the original package, Elliott et al. conducted comparisons with results from older, slower integrators in a variety of tropospheric chemical settings (1995b). For example: the Shaw Liu group at NOAA in Colorado has calibrated their tropospheric chemistry model against a number of measurements at Niwot Ridge in the Rocky Mountains. Their results are shown as the dashed curves in Figure 5. Agreement is excellent for pure $\mathrm{CO} /$ methane runs and those with the natural hydrocarbon input represented as isoprene. The discrepancy for simulations embracing the full suite of 
nonmethane hydrocarbons is due to variation in treatment of dilution processes in the boundary layer. The Elliott et al. (1995b) report also describes tests of the ability of the Mei Shen model to capture ozone production in the tropospheric column following convective events.

Several low dimensionality applications have been found for the Mei Shen tropospheric chemistry programs. Shen has developed a one-dimensional model of the full troposphere that is capable of representing oceanic or continental air masses at middle to high latitudes. An unusual data presentation mode is adopted in Figure 6. Ozone concentrations are displayed beginning from an initial value of $40 \mathrm{ppbv}$ at all altitudes, then entering into the standard seasonal cycle as a function of NMHC levels. The code has been used to elucidate the role of terpenoid compounds in tropospheric kinetics at boreal sites in the Canadian North and Alaska, and in the heavily vegetated US Southeast (Shen et al., 1996).

Elliott et al. (1996a) have tailored the storm redistribution version of the program to the special case of tropical urban pollution. The polluted plume extending away from Manaus, Brazil was taken as a case study. Significant ozone production enhancements were found for the free tropospheric column at surface plume nitrogen oxide levels of as little as $300 \mathrm{pptv}$. Gaussian plume areas were calculated during both the rainforest dry and wet seasons, and were as large as tens of thousands of square kilometers.

Most recently, the Mei Shen model has been reconfigured in two dimensions in order to compute ozone production in the geostrophic westerlies flowing off the Asian continent in spring (Elliott et al. 1996b). Preliminary calculations indicate that the mainland Chinese vehicular transportation system holds the potential to generate massive ozone pollution over Japan and the Western Pacific. Runs including emissions of volatile organics and nitrogen oxides from 50 million, 150 million and 450 million new automobiles produce many tens of ppbv of oxidants in the lowest few kilometers off the Chinese coast.

\section{(b) Development of Methods for the Characterization of}

Heterogeneous Atmospheric Processes. This subproject developed a unique aerosol analysis technique, aerosol time-of-flight mass spectrometer (ATOFMS). This instrument allows real-time analysis of the size and chemical composition of individual aerosol particles. This instrument was used to study aerosols from the ambient atmosphere to establish size/composition profiles of atmospheric aerosols for use in global and regional atmospheric models. Since ATOFMS is portable, it can analyze in situ both particle size and composition (Figure 7). This allows more accurate source apportionment than current 
analytical methods. The ATOFMS is also being used to monitor heterogeneous reaction processes simulating particles from the atmosphere in controlled experiments in the laboratory. These study heterogeneous processes on thin films that simulate stratospheric and tropospheric aerosol surfaces. Adsorption of water on nitric acid trihydrate (NAT) films, which mimic processes occurring on polar stratospheric clouds, is measured. We have shown that the analogous model describes both the relative humidity and temperature dependence on the reactions of $\mathrm{CLONO}_{2}$ with water and HCL on NAT. For further details see Henson et al (1996) in the publications list.

(c) Modeling of Sulfur Emissions Across the Arctic with a Global Atmosphere Code. Use of a Los Alamos Lagrangian particle numerical scheme in the global climate model to track sulfur emissions across the Arctic gave outstanding results due to subgrid-scale capabilities of the method, reproducing weather details thought to be possible only with much finer zoning.

In an attempt to better understand Arctic haze and the fate of biogenic emissions of sulfur from the Arctic Ocean, the Los Alamos General Circulation Model was run with Lagrangian particles injected to simulate a time-dependent point source of sulfur pollution. It was hoped that the tracer particles would approximate a more finely resolved computation. In fact they did, not only in tracing the movement of the pollution as weather fronts passed by, but also in defining the gradients of potential vorticity. In addition they showed a surprising ability to delineate a process for moving particles from polar to lower mid-latitudes called "Rossby wave breaking". The calculation shows particles being accumulated by weather fronts and subsequently breaking out along narrow paths that are southward directed. These narrow breakouts appear to be caused by the Rossby wave breaking, a phenomenon heretofore thought to be restricted to the stratosphere. Further corroboration resulted from the generally good agreement between Lagrangian tracer contours and those of isentropic potential vorticity.

\section{Mathematical Physics Improvements: Approximate Inertial Manifolds and Numerical Computations}

The main goal of this subproject was to attempt to improve ocean circulation codes by finding subgrid-scale properties and long-time dynamics of dissipative evolution equations. In general, these are infinite-dimensional dynamical systems that exhibit finitedimensional asymptotic behavior. One would like to take advantage of such finitedimensional asymptotic dynamics to design, for example, better ways to control the infinite-dimensional system or to develop more accurate and efficient numerical schemes to approximate its global attractor. In the context of the Navier-Stokes equations, we find an 
estimate of the size of the computational mesh that guarantees reliable resolution of turbulence. In this framework we found an application of the Strommel-Charney Equation to a model of the behavior of the Gulf Stream, which showed that its behavior can be treated by an Approximate Inertial Manifold (AIM), i.e. it contains attractor-like organization. Carrying this approach a step further we have made progress in applying AIMs to numerical computations of ocean models. We have developed a finite-difference version of AIMs for the shallow water model equation, which has successfully run the simulations with a large savings in computing time with no loss in accuracy.

\section{PUBLICATIONS}

Albertson, J.D., Kiely, G., Parlange, M.B., and Eichinger, W.E. The average dissipation rate of turbulent kinetic energy in the neutral and unstable atmospheric surface layer, submitted to J. of Geophys. Res., (1995)

Albertson, J.D., Parlange, M.B., and Eichinger, W. Estimates of Sensible and Latent Energy Fluxes from the Standard Deviations of Air Temperature and Specific Humidity, Abstract, Spring Meeting, American Geophysical Union, May 23-27, Baltimore, Maryland, p. 173 (1994).

Chen, F. and M. Ghil, 1995a: Interdecadal variability of the thermohaline circulation and high-latitude surface fluxes. J. Phys. Oceanogr., in press.

Chen, F. and M. Ghil, 1995b: Inter decadal variability in a hybrid coupled oceanatmosphere model, J. Phys. Oceanogr., submitted.

Chen, S.-C., Norris, C.L., and Roads, J.O. 1995: Balancing the atmospheric hydrologic budget. J. Geophys. Res. (in press).

Cockburn, B., Jones, D., and Titi, E.S. 1995, "Estimating the number of asymptotic degrees of freedom for nonlinear dissipative systems," submitted to Mathematics of Computation.

Cooper, D. I. , W.E. Eichinger, S. Barr, W. Cottingame, M.V. Hynes, C.F. Keller, C.F. Lebeda, and D.A. Poling, High-Resolution Properties of the Equatorial Pacific Marine Atmospheric Boundary Layer from Lidar and Radiosonde Observations, Jour. of Atmospheric Sci., p. 1388, (June, 1996)

Eichinger, W.E. , D.I. Cooper, D.B. Holtkamp, R.R. Karl, C.R. Quick and J.J. Tiee, Derivation of Water Vapor Fluxes from Lidear Measurements, Boundary-Layer Meteorology, 63, p. 39-64, (1993)

Eichinger, W., Parlange, M., Cooper, D., and Cottingame, W. Surface Flux Measurements Aboard the R.V. Vickers During the Central Equatorial Pacific Experiment, American Meteorological Society Symposium on the Regulation of Sea 
Surface Temperatures and Warming of the Tropical Ocean Atmosphere System, January 15-20, Dallas, Texas (1995).

Eichinger, W.E., Parlange, M.B., and Cooper, D.I. Raman Lidar Observations of Cirrus Cloud Properties During the Central Equatorial Pacific Experiment, American Meteorological Society Symposium on the Regulation of Sea Surface Temperatures and Warming of the Tropical Ocean Atmosphere System, January 15-20, Dallas, Texas (1995).

Elliott, S., D.R. Blake, F.S. Rowland, R. Lu, M. Brown, M. Williams, A.G. Russell, J.E. Bossert, G. Streit, W. Porrch, G. Guzman, L. McNair, C.Y.J. Kao, R.P. Turco, W. Eichinger, "Ventilation of Liquified Petroleum Gas Components from the Valley of Mexico", submitted to J. Geophys. Res., May 1996.

Elliott, S., C.Y.J. Kao, D.R. Blake, M. Shen, F.S. Rowland, R. Lu, A. Russell, R.P. Turco, 1996,"Regional to Global Atmospheric Effects on the Emerging Mainland Chinese Transportation System", submitted to J. Atmos. Chem.

Elliott, S., Kao, C.Y.J., Gifford, F., Barr, S., Shen, M., Turco, R.P., and Jacobson, M. Z., 1996. Free tropospheric ozone production after deep convection of dispersing tropical urban plumes. Submitted to Atmospheric Environment.

Elliott, S., Kao, C.Y.J., Shen, M., Turco, R.P., and Jacobson, M. Z., 1995. A streamlined family photochemistry package reproduces major nonlinearities in the tropospheric ozone system. Computers and Chemistry, in press.

Elliott, S. and Rowland, R.S., "Methyl halide hydrolysis rates in natural waters", J. of Atmos. Chem. 20, p. 229, (1995)

Elliott, S., Turco, R.P., Zhao, X.P., Kao, C.Y.J. and Shen, M., "Photochemical numerics for global scale modeling: fidelity and GCM testing." J. of Applied Meteorology 34, p. 694 (1995)

Fuehrer, P.L. and Friehe, C.A., 1995, "A Structural Model for Turbulence in the Atmospheric Boundary Layer" (submitted to Phys. of Fluids)

Henson, B.F., K.R. Wilson, and J.M. Robinson, "A Physical Adsorption Model of the Dependence of $\mathrm{ClONO}_{2}$ Heterogeneous Reactions on Relative Humidity", Geophys. Res. Lett., 23, p. 1021, (1996)

Jones, D. and Titi, E.S., 1995, "C1 Approximating Inertial Manifolds for the Dissipative Nonlinear Equations", J. Diff. Eqns. (In Press)

Kao, C.Y. J., A. Quintanar, M.J. Newman, D.L. Langley, W.E. Wichinger, and S. C. Chen, "Climate Simulations with NCAR CCM2 forced by global sea surface temperatures 1950-1989", Journal of Climate, (to appear, November 1996)

Kao, C.Y. J., S. Varr, A. Quintanar, D.L. Langley, G.A. Glatzmaier, and R. C. Malone, "Numerical modeling of tracer transport within and out of the lower tropospheric Arctic region", Geophys. Rev. Lett., 22, p. 941, (1995) 
Kiely, G., Albertson, J.D., Parlange, M.B., and Eichinger, W.E. On the scaling of the average dissipation rate of temperature variance in the atmospheric surface layer, submitted to Boundary-Layer Meteorology, (1995)

Marshall, S., J.O. Roads, and G.A. Glatzmaier, "Snow Hydrology in a General Circulation Model," J. Climate, 7, 1252-1269, (1994)

Noble, Christopher A. and K.A. Prather, "Real-time Measurement of Correlated Size and Composition Profiles of Individual Atmospheric Aerosol Particles", Environ. Sci. and Technol., 30, p. 2667, (1996)

Norris, C., J. Roads, S. Chen, and P. Weber, "Global precipitable water estimates from SSM/I", Proceedings of the AGU 1994 Special Session on Hydrometeorology, San Diego, California, March 7-10, (1994)

Parlange, M., Eichinger, W., and Albertson, J. Evaporation and the Atmospheric Boundary Layer, in press, Reviews in Geophysics, Spring 1995.

Parlange, M., Eichinger, W., and Katul, G.: Lidar Measurements of the Scalar Similarity Function in the Unstably Stratified Turbulent Atmosphere, submitted to Phys. Rev., December 1994.

Robertson, A. W. , 1995 "Interdecadal Variability of the North Pacific in a Multi-century Climate Simulation", Climate Dynamics (In Press)

Smith, W.S., and C.-Y.J. Kao, "Numerical Simulations of Arctic Stratus Clouds Using a Second Order Turbulence Closure Model", J. Appl. Meteorol., 35, p. 47, (1996)

Smith, W.S., and C.-Y.J. Kao, "Using a turbulence radiative-convective model to study the cloud/radiation interaction with the FIRE data", Mon. Wea. Rev. 8, p. 1803, (1996)

Zhao, X.-P., R. P. Turco, C.-Y. Jim Kao, and S. Elliott, "Numerical Simulation of the Dynamical Response of an Arctic vortex to aerosol associated chemical perturbations in the lower stratosphere", Geo. Res. Letters, 12, p. 1525, (1996)

Zhao, X., Turco, R.P., Kao, C.Y.J. and Elliott, S. 1996. GCM simulations of the chemical perturbations related to stratospheric aerosols. J. of Geophys. Res. In Press

\section{REFERENCES}

Chen, S-C., J. Roads, and J.C. Alpert, "Variability and predictability in an empirically forced global model", J. Atmos. Sci., 50, p. 443 (1993).

Cubasch, U., K. Hasselmann, H. Hoeck, E. Maier-Reimer, U. Mikolajewicz, B.S. Santer, and R. Sausen, "Time-dependent greenhouse warming computations with a coupled ocean-atmosphere model", Climate Dynamics, 8, p. 55 (1992)

Elliott, S., Turco, R.P., Zhao, X.P., Shen, M. and Kao, C.Y.J., Efficient and modular kinetics packages for global scale photochemical modeling. In: The Role of Meteorology in Managing the Environment of the Nineties, A. Roffman (Editor), AWMA Specialty 
Conference Proceedings, Air and Waste Management Association, Pittsburgh: 73-84 (1993a).

Elliott, S., Kao, C.Y.J., Turco, R.P. and Zhao, X.P., Kinetics programs for simulation of tropospheric photochemistry on the global scale. Los Alamos National Laboratory Technical Report LA12539-MS, 72 pp (1993b).

Elliott, S., Turco, R.P., Zhao, X.P., Kao, C.Y.J. and Shen, M., Photochemical numerics for global scale modeling: fidelity and GCM testing. J. of App. Meteorol. 34(3): 694-718 (1995a).

Elliott, S., Kao, C.Y.J., Shen, M., Turco, R.P. and Jacobson, M.Z., A streamlined family photochemistry package reproduces major nonlinearities in the tropospheric ozone system. In press, Computers and Chemistry (1995b).

Elliott, S., Kao, C.Y.J., Gifford, F., Barr, S., Shen, M., Turco, R.P., and Jacobson, M. Z., Free tropospheric ozone production after deep convection of dispersing tropical urban plumes. Submitted to Atmospheric Environment (1996a).

Elliott, S., C.Y.J. Kao, D.R. Blake, M. Shen, F.S. Rowland, R. Lu, A. Russell, R.P. Turco, "Regional to Global Atmospheric Effects on the Emerging Mainland Chinese Transportation System", submitted to J. Atmos. Chem. (1996b).

Kao, C.Y. J., 1992: A nonlinear feedback in climate modeling associated with cumulus parameterizations. Physica D. 60, p. 62, (1992)

Shen, M., Turco, R.P. and Paulson, S.E. 1996. Role of isoprene in tropospheric photochemistry and ozone production. Submitted to J. Geophys. Res.

Smith, R.D., J.K. Dukowicz, and R.C. Malone, "Parallel ocean general circulation modeling", Physica D, 60, p. 38 (1992)

Sundqvist, H., "Parameterization of condensation and associated clouds in models for weather prediction and general circulation simulation" In Physical based modelling and simulation of climate and climatic change. M. Schlesinger (ed.), Reidel, Dordrecht, p. 433, (1988)

Zhao, X., Turco, R.P., Kao, C.Y.J. and Elliott, S. 1995. Numerical simulation of the dynamical response of the Arctic vortex to aerosol associated chemical perturbations in the lower stratosphere. Submitted to Geophys. Res. Lett.

Zhao, X., Turco, R.P., Kao, C.Y.J. and Elliott, S. 1996. GCM simulations of the chemical perturbations related to stratospheric aerosols. Submitted to J. of Geophys. Res. 

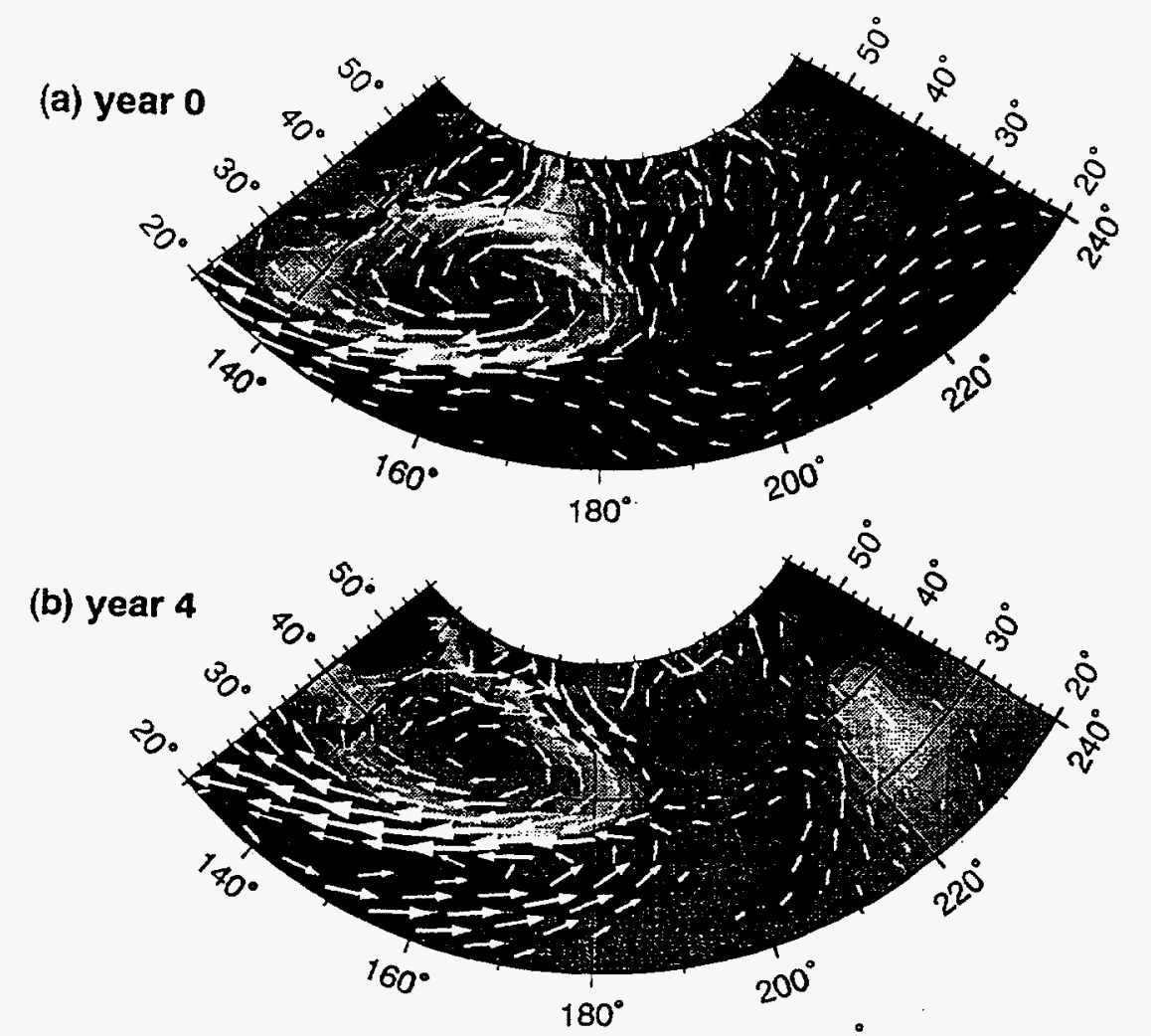

(c) year 8

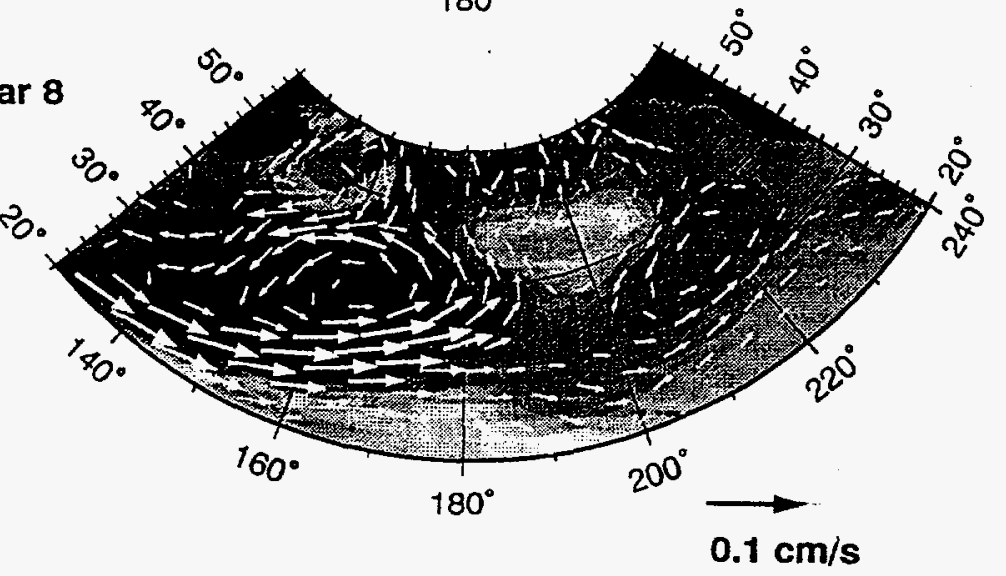

Figure 1. Composite maps of the accompanying sub-surface ocean thermal and current anomalies. Year 0 designates the phase of the peak warm SST anomaly over the western Pacific; year 4 is the approximate quadrature phase of the oscillation, and year 8 is nearly one-half period after year 0 . 


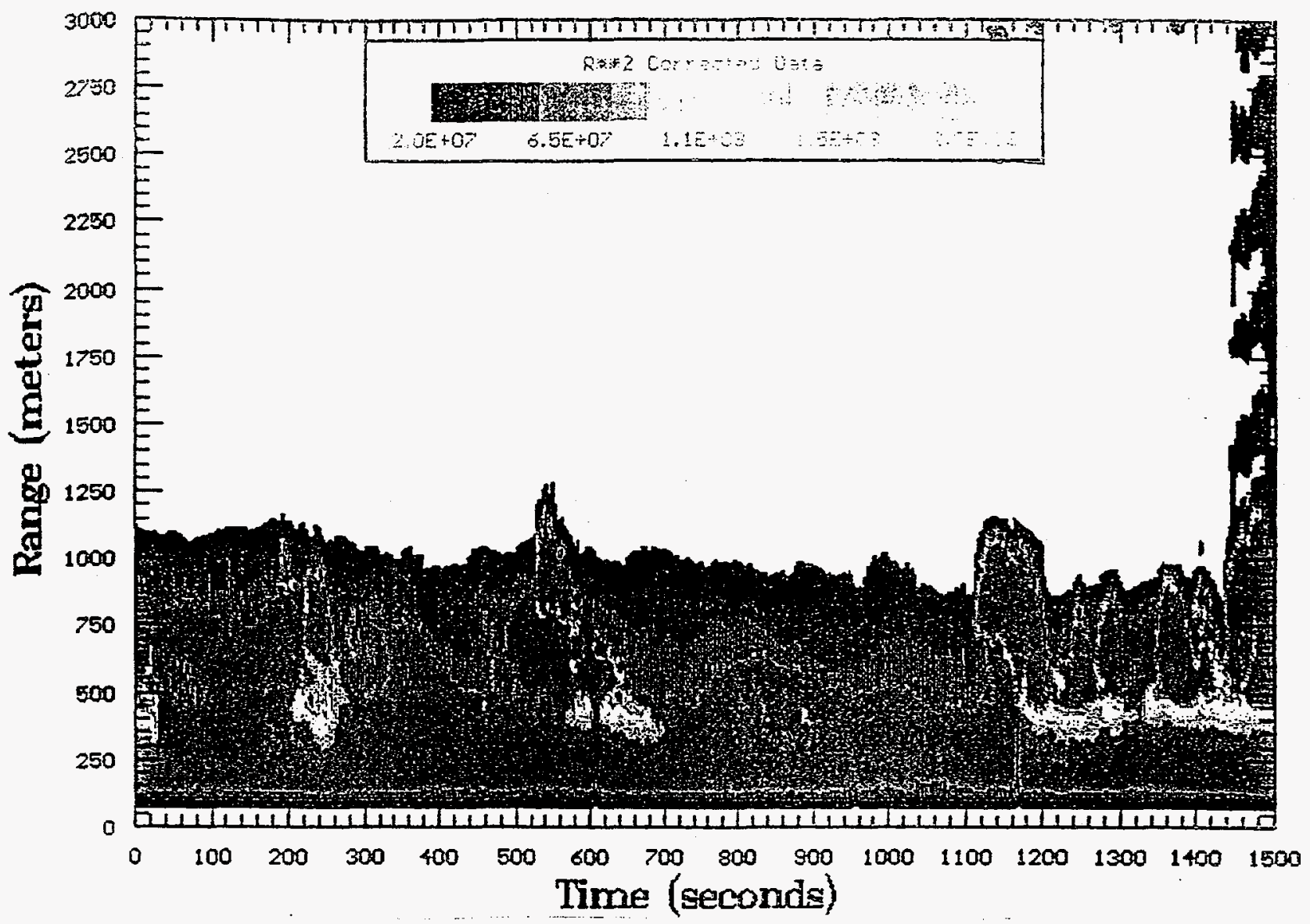

Figure 2. A lidar time-altitude (as the ship sails along) plot of aerosol concentrations near the ocean surface. Light section are clouds that form at the top of the marine boundary layer. 


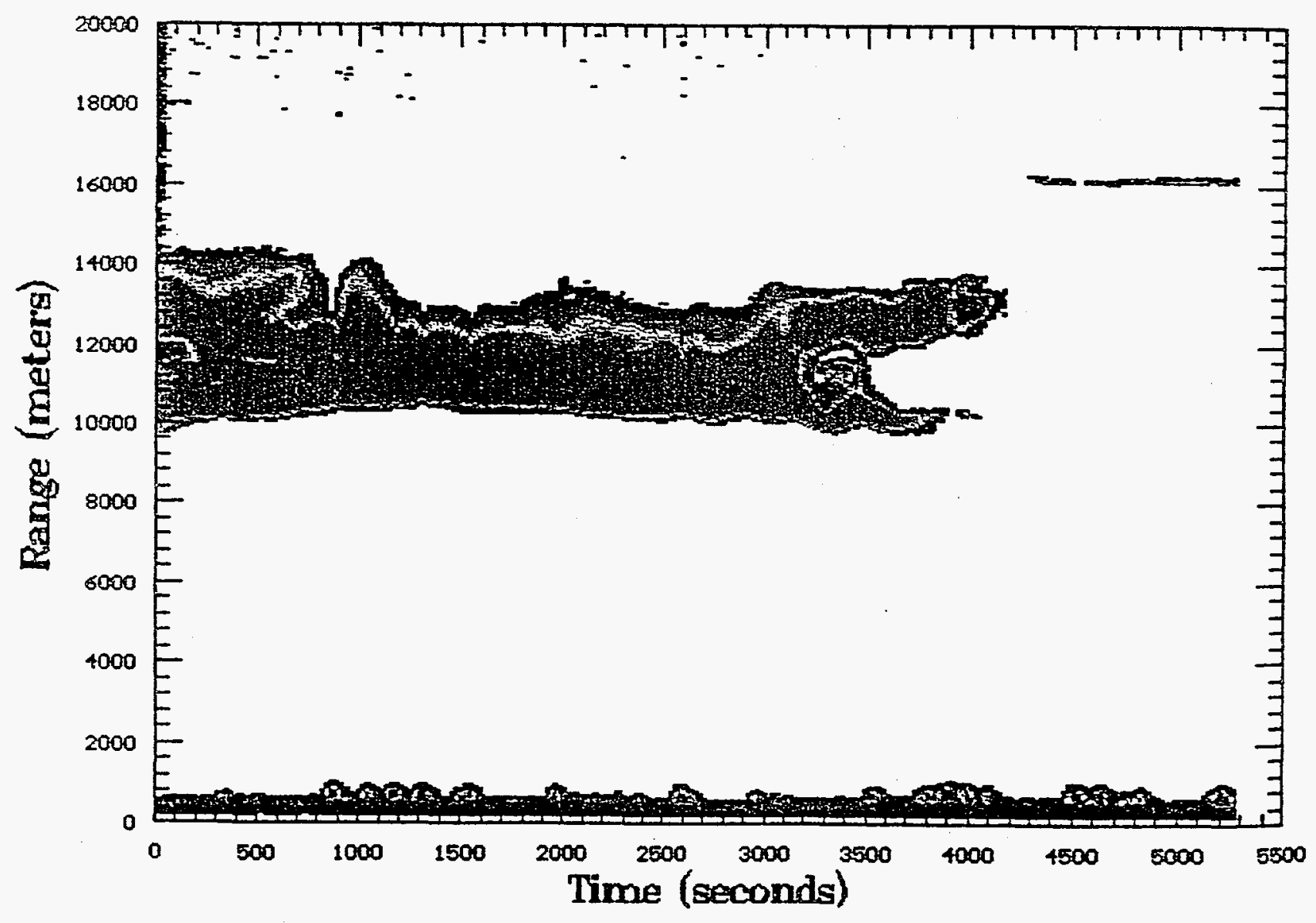

Figure 3. A lidar time-altitude (as the ship sails along) plot of aerosol concentrations. The cloud bank shown at $10-14 \mathrm{~km}$ altitude is a remnant of earlier deep convective activity. From this data, the cloud physical and optical properties can be derived. A thin cloud layer can also be seen in the upper right of the figure. This layer at $16 \mathrm{~km}$ is thin cirrus that forms near the tropopause. 
SUNAS January $1982-1989$ ave precipitation TPRECIP $\mathrm{mm} /$ day

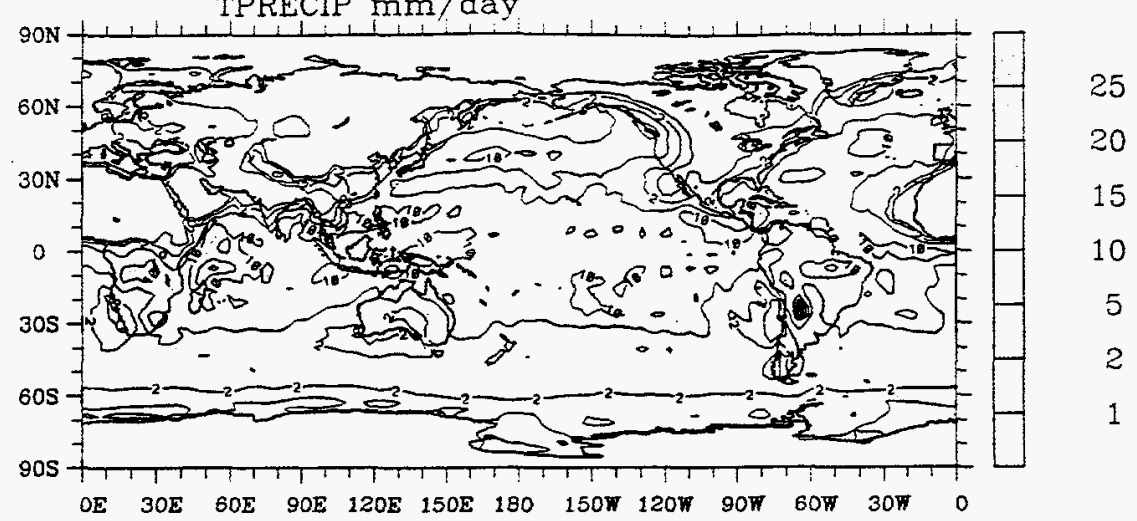

CCM2 January $1982-1989$ ave precipitation TPRECIP $\mathrm{mm} /$ day
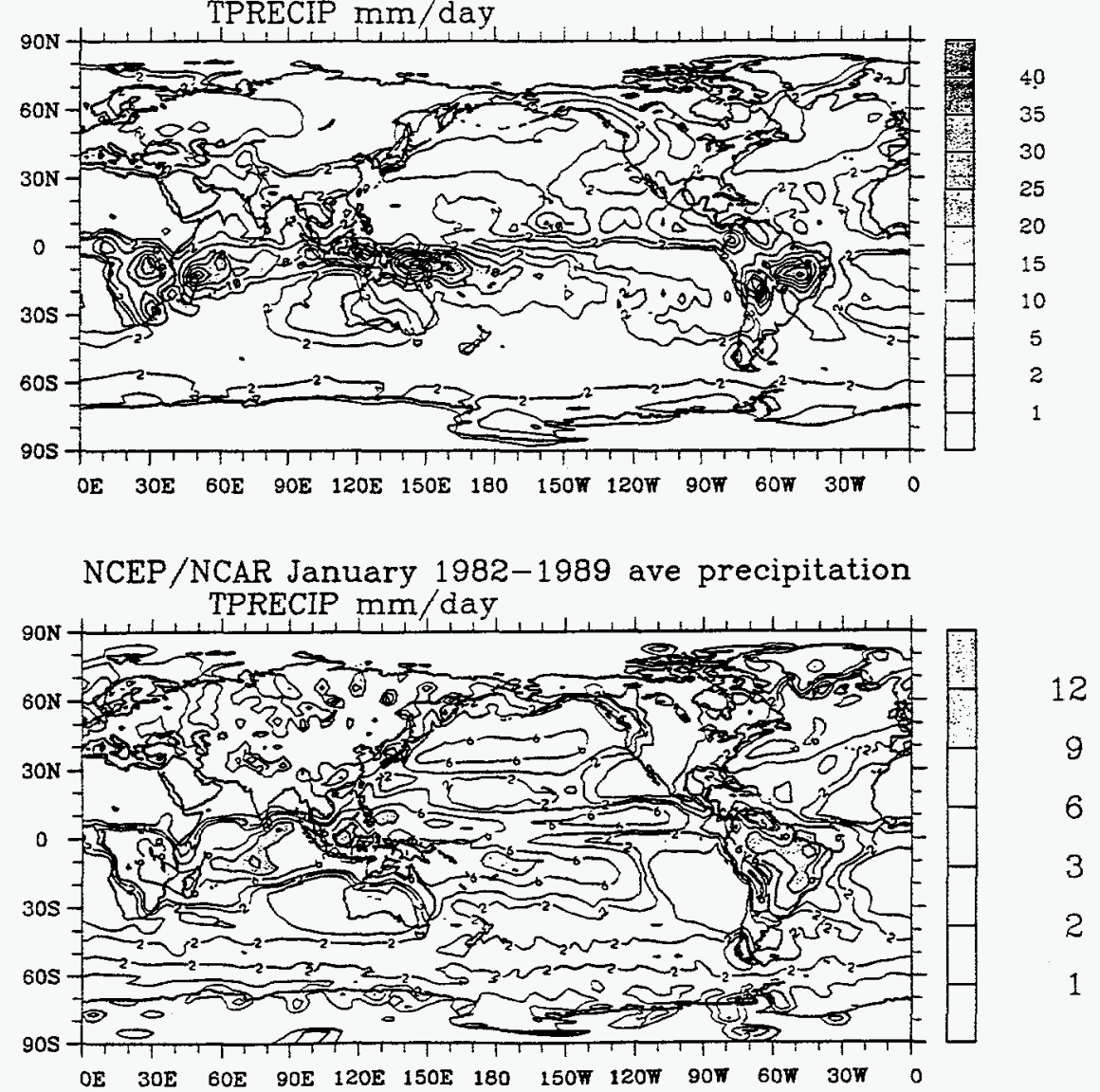

Figure 4. Global plots of precipitation in mm/day comparing CCM2 code with Los Alamos SUNAS simulations (top), CCM2 with NCAR cloud parameterizations (middle), and model-interpolated data set of actual precipitation (bottom). 


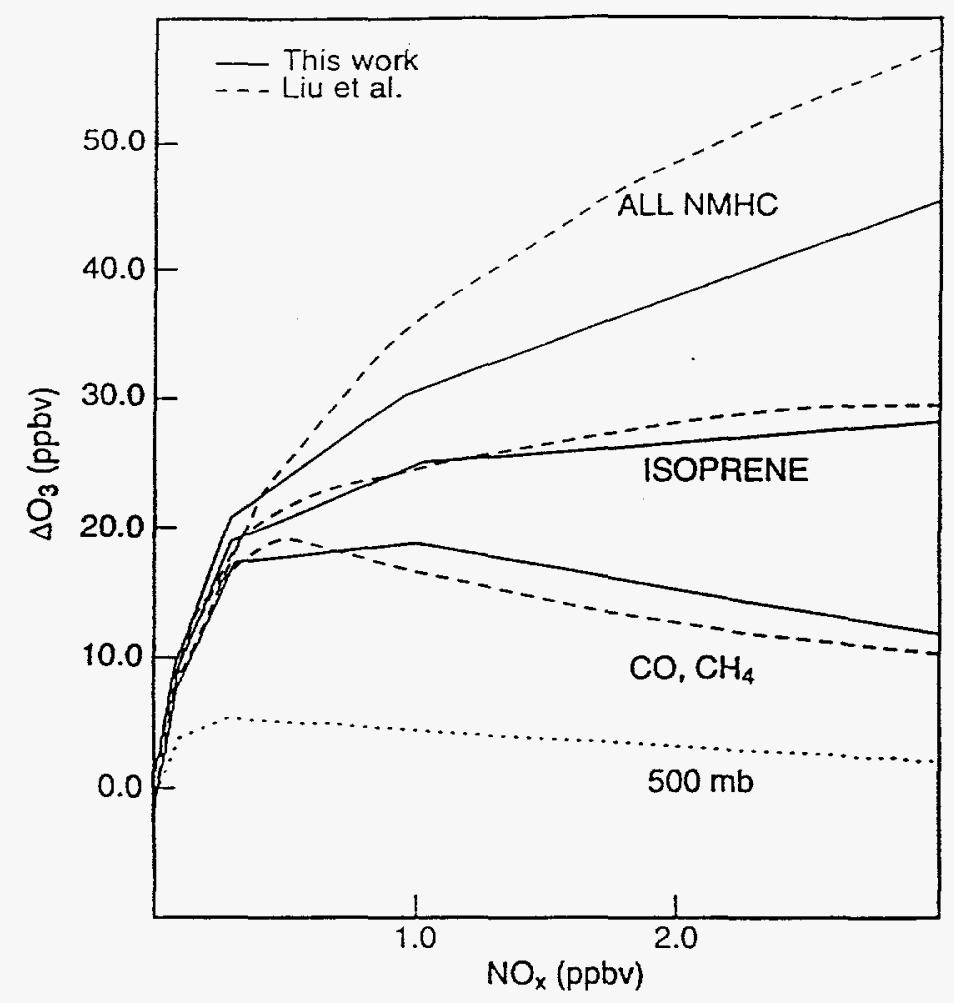

Figure 5. A comparison of ozone production simulations at the surface of the Niwot Ridge site (above Boulder $\mathrm{CO}$ ). 


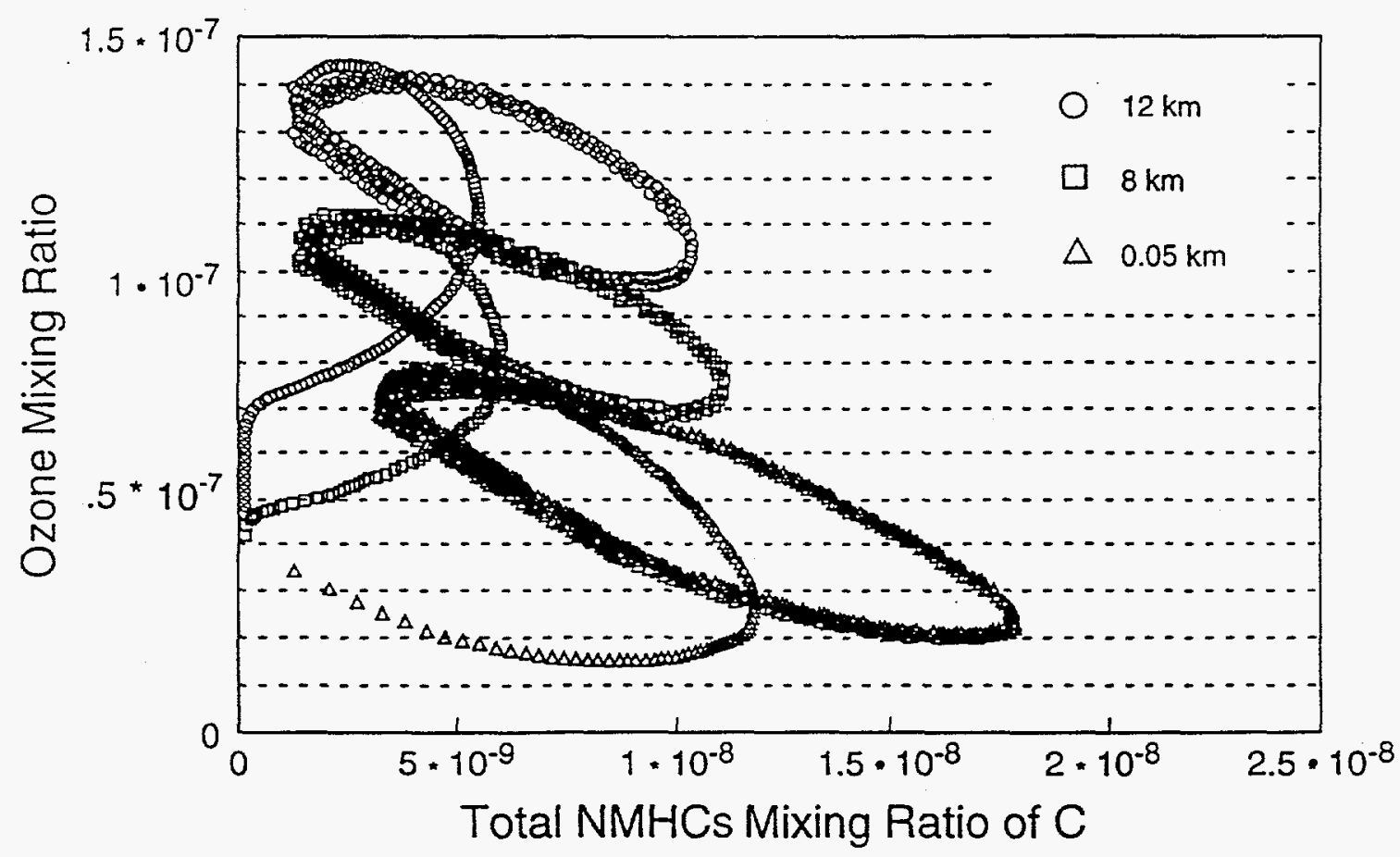

Figure 6. Ozone enters into its seasonal cycle at three tropospheric altitudes as simulated by the one-dimensional Mie Shen code 


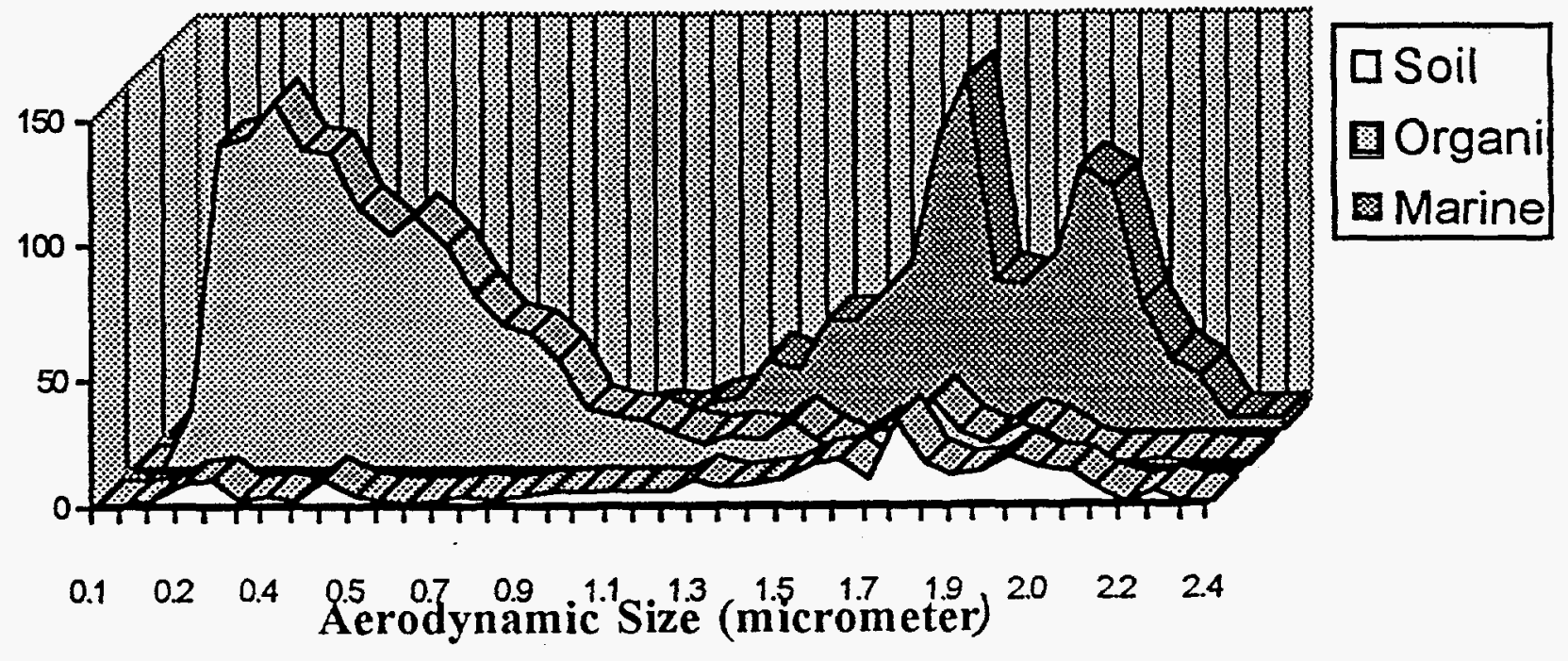

Figure 7. Aerosol data from time-of-flight mass spectrometer (ATOFMS). The particle size distribution is broken down into three common particle sources. 